\title{
Students still ambivalent about family medicine
}

The 2004 residency match has proved a mixed blessing for family medicine.

of At the end of the first round of the match on Mar. 24, 124 family practice slots remained vacant. This actually marked a drop of 15 vacant positions from last year. About $23 \%$ of

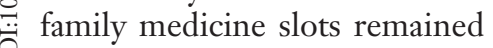
$\AA$ unclaimed after the first round

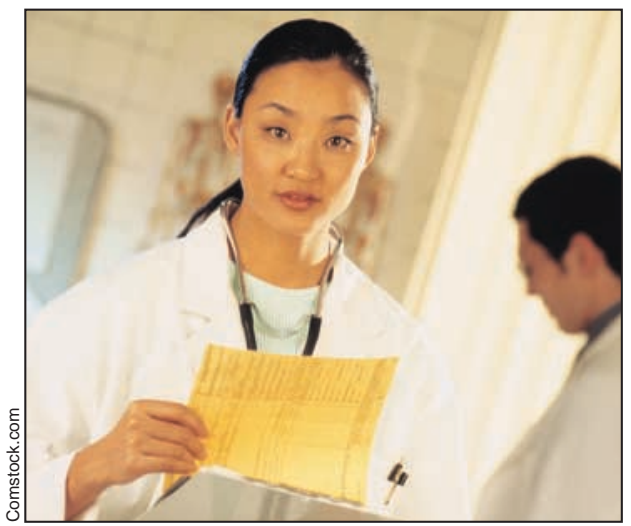

About $23 \%$ of family medicine residency spots were left vacant after the first round of the match. in 2004 , compared with $29 \%$ last year.

The only other specialty in double digits this year was psychiatry, at $10 \%$.

The number of positions in the match increased by 45 this year, to 1404 . In the end, 1312 people applied, reports the Canadian Resident Matching Service.

New graduates' ambivalence toward family medicine was made clear by the fact it accounted for $70 \%$ of all unfilled positions after the first round - the same proportion as last year.

A 2004 graduate who matched to family medicine said "some people who desperately wanted competitive specialties but backed up with family medicine - and got the latter were as or more upset than the unmatched folks."

Overall, 71 Canadian graduates remained unmatched after the first iteration, but because
177 positions remained unfilled, most of them should match easily when the second iteration is held Apr. 29.

New Canadian graduates' apparent lukewarm feelings for family medicine are shared south of the border.

In the US match, held a week before Canada's, the number of American graduates matching to family medicine declined for the 7 th year in a row.

Although 2256 positions in family medicine were eventually filled, only 1185 went to graduates of American medical schools; the rest were filled by international medical graduates.

Dr. Michael Fleming, president of the American Academy of Family Physicians, said US family physicians have to do a better job selling their specialty within the US schools because IMGs "tend to return to their own countries." - Patrick Sullivan, CMA 